(2) Open Access Full Text Article

REVIEW

\title{
Immune-mediated keratoconjunctivitis sicca in dogs: current perspectives on management
}

This article was published in the following Dove Press journal:

Veterinary Medicine: Research and Reports

30 October 2015

Number of times this article has been viewed

\section{Pier Luigi Dodi}

Department of Veterinary Medicine Sciences, University of Parma, Parma, Italy
Correspondence: Pier Luigi Dodi

Department of Veterinary Medicine

Sciences, University of Parma, Strada del

Taglio, 8-43I 26 Parma, Italy

Tel +39052I 032673

$\mathrm{Fax}+390521032692$

Email pierluigi.dodi@unipr.it

\begin{abstract}
Keratoconjunctivitis sicca (KCS) is a frequent canine ophthalmic disease, resulting from the deficiency of one or more elements in the precorneal tear film. There are different known causes of KCS in dogs, including congenital, metabolic, infectious, drug induced, neurogenic, radiation, iatrogenic, idiopathic, and immune mediated, though the last one is the most prevalent form in dogs. Initially, clinical signs of KCS include blepharospasm caused by ocular pain, mucoid to mucopurulent ocular discharge, and conjunctival hyperemia; secondary bacterial infection may also occur, with chronicity, corneal epithelial hyperplasia, pigmentation, neovascularization, and corneal ulceration. The diagnosis of KCS is based on the presence of consistent clinical signs and measurement of decreased aqueous tear production using the Schirmer tear test. Therapy is based on administering the following topical drugs: ocular lubricant, mucolytics, antibiotics, corticosteroids, pilocarpine, and immunomodulators. These last drugs (eg, cyclosporine, pimecrolimus, and tacrolimus) have immunosuppressive activity and stimulate tear production. Furthermore, the nerve growth factor is a new subject matter of the research. Although these therapies are advantageous, stimulation of natural tear production seems to provide the highest recovery in clinical signs and prevention of vision loss. The goal of the following article is to describe the recent developments about KCS in dogs emphasizing the use of new therapies.
\end{abstract}

Keywords: dogs, keratoconjunctivitis sicca, treatment, NGF

\section{Introduction}

Keratoconjunctivitis sicca (KCS), also known as dry eye syndrome, is a chronic ophthalmic disease resulting from deficiency of one or more elements in the precorneal tear film. ${ }^{1}$

It is a common canine eye disease, with reported annual incidences of $0.3 \%-1.52 \%$ in North America. ${ }^{2-5}$ It is also very common in Europe.

$\mathrm{KCS}$ can be divided into two types: the symptoms of one consists of decreased tear production or inadequate secretion of tears, and the symptoms of the other includes excessive tear evaporation, which is typical of brachycephalic breeds. ${ }^{6,7}$ Furthermore, the precorneal tear film instability is due to both quantitative and qualitative deficiency in the lipid or mucine layers of tear film. ${ }^{1}$ Unfortunately, the reduction in tear production causes corneal inflammation, and in very severe cases, it can cause a permanent harm or even blinding. ${ }^{8}$

$\mathrm{KCS}$ is a pathology of the lacrimal apparatus. It is divided into the secretory and the excretory structures. The first group is made up of lacrimal glands and meibomian glands, and goblet cells and their products make up the preocular tear film. The other 
group is made up of the lacrimal canaliculi, the lacrimal sac, and the nasolacrimal duct.

Tears play an important role in maintaining the health and normal function of the cornea and conjunctiva. Precisely, the functions of tears are lubrication, nutrition of the cornea, and flushing debris from corneal surface, and tears contain growth factors, as in the case of nerve growth factor (NGF), immunoglobulins, lysozymes, and other components of the ocular defense mechanisms with antibacterial action..$^{9-11}$ The tear film has three different layers: a mucus layer produced by conjunctival goblet cells, close to the corneal epithelial surface, an aqueous layer produced by lacrimal glands, and a lipid component produced mainly by the meibomian glands in the upper and lower eyelids. A most superficial layer of meibomian lipid (made mainly by cholesterol) acts to reduce evaporation and to make the tear film stable. More recently, studies have shown that this cut-and-dried distinction between layers is not strictly correct because of the very strict relationship among the proteic substances that make up the three layers. ${ }^{12}$

\section{Etiology}

There are several known causes of KCS in dogs, including congenital, metabolic, infectious, drug induced, neurogenic, radiation, iatrogenic, idiopathic, and immune mediated.

Congenital: It is a genetic, congenital alacrima observed in the Yorkshire Terrier, Bedlington Terrier, English Cocker Spaniel, and Cavalier King Charles Spaniels. ${ }^{13-15}$ For this, last breed KCS is associated with ichthyosiform dermatosis (dry eye curly coat syndrome). ${ }^{16-18}$

Metabolic: It is caused by diabetes mellitus and hypothyroidism. ${ }^{19,20}$

Infectious: It is caused by a canine distemper virus or by leishmania. ${ }^{1,71,22}$ With these diseases, KCS is part of the systemic symptoms occurring with this infection.

Drug induced: KCS may be temporary or permanent according to the toxic effects on the gland. Temporary KCS is due to local or systemic anesthetic, the sedatives, and the atropine. ${ }^{23}$ If the use is interrupted, there will be a general return to ordinary conditions. Permanent KCS is a quite common side effect of potentiated sulfonamides in dogs. It has an estimated incidence of $15 \%$ in treated dogs even with Etodolac, that is, an orally administered, nonsteroidal anti-inflammatory drug and with Felbamate, that is, an antiepileptic drug. ${ }^{24-27}$

Neurogenic: This type of KCS can show ipsilateral dry nose in middle-aged female dogs without breed predisposition. It is an idiopathic disease that may be self-limiting in some cases. ${ }^{28}$
Radiation: In case of radiation therapy in some cases, there can be a damage of the lacrimal glands but luckly it is a less common cause of KCS in dogs. ${ }^{29}$

Iatrogenic: It is due to the surgical removal of the gland of the third eye in case of "cherry eye". ${ }^{30}$ If this procedure is done in predisposed breeds, then KCS will be developed late in their lifetime. ${ }^{31-33}$ The reason is that the third eye gland is responsible for $30 \%$ of the tear production, while the main orbital lacrimal gland produces the rest. ${ }^{4,34}$

Idiopathic: In the vast majority, an underlying etiology is not discernable. ${ }^{1}$

Immune mediated: It is a widely primarily accepted cause of KCS. As already underlined, it is the main cause of immune-mediated dacryoadenitis in dogs. ${ }^{5}$ It is generally bilateral, ${ }^{35}$ and a confirmation of the fact that KCS is an immune-mediated disease is offered by the histopathology of tear production glands. Some previous histopathological studies suggest that in these cases KCS is the result of immune-mediated inflammation and destruction of the lacrimal glands. ${ }^{36,37} \mathrm{~A}$ further confirmation of this cause is the clinical response to the immunomodulators such as CsA, pimecrolimus, and tacrolimus. ${ }^{1,11,38,39}$ Breed prevalence of immunomediated KCS in clinical research made in UK and in the USA is Cavalier King Charles Spaniels, English Bulldogs, Lhasa Apsos, Shih Tzus, West Highland White Terriers, Pugs, Bloodhounds, American Cocker Spaniels, English Cocker Spaniels and English Springer Spaniels, Pekingeses, Boston Terriers, Miniature Schnauzers, and Samoyeds (Table 1). ${ }^{2,40}$ The KCS is also familiar with factors such as sex, age, and palpebral conformation. It is common to find it in female West Highland White Terriers. ${ }^{15}$ Tear production decreases with age in normal dogs; it is, in fact, more frequent in

Table I Main breed predisposition

American Cocker Spaniel
Bloodhound
Boston Terrier
Cavalier King Charles Spaniel
English Bulldog
English Cocker Spaniel
English Springer Spaniel
Lhasa Apso
Miniature Schnauzer
Pekingese
Pug
Samoyed
Shih Tzu
West Highland White Terrier
Yorkshire Terrier

American Cocker Spaniel

Bloodhound

Boston Terrier

Cavalier King Charles Spaniel

English Cocker Spaniel

English Springer Spaniel

Lhasa Apso

Miniature Schnauze

Shih Tzu

Yorkshire Terrier 
older animals than in younger ones. In case of palpebral ectropion and lagophthalmos, it increases the evaporation of the tears and facilitates the uprising of KCS, especially in brachycephalic dog breeds.

\section{Clinical features}

Clinical signs of KCS can vary according to gravity and to the onset of the illness. At the very beginning, KCS appears as a common conjunctivitis or as a mucopurulent one. It is the reason why it is diagnosed as a banal primary bacterial infection and it is treated with antibiotics. It is obvious that the improvement is only temporary, and the dry conditions of the eye show limited better conditions due to the use of an antibiotic or a corticosteroid. Once the therapy is interrupted, the situation will be the same and sometimes worse than at the beginning.

During the first phases of the disease, the ocular surface is less bright. The conjunctiva is extremely reddish, and it is always evident a very dense yellow and gray discharge. As the disease becomes chronic, KCS manifests corneal vascularization, fibrosis, pigmentation, and recurrent corneal ulceration. Blindness or even loss of the eye may result from dense corneal opacification or corneal perforation secondary to deep ulceration (Table 2). ${ }^{1}$ Thankfully blindness affects only a small group of animals. The owner should know that this is possible, and in case of blindness, the veterinary doctor should inform about the management of the patient and the possible surgery treatment. This is the reason why an early diagnosis is of vital importance, in particular to give the best possible therapy.

Table 2 Stage of KCS

\begin{tabular}{ll}
\hline Stages & Clinical signs \\
\hline Initial & - Mucopurulent ocular discharge \\
& - Conjunctival hyperemia \\
& - Blepharospasm \\
& \\
Intermediate & - Intense mucoid ocular discharge \\
& - Corneal opacification \\
& - Corneal vascularization \\
Final & - Fibrosis \\
& - Recurrent corneal ulceration (possible \\
& corneal perforation and blindness) \\
&
\end{tabular}

Abbreviation: KCS, keratoconjunctivitis sicca.

\section{Schirmer tear test}

The best instrument to use in case of KCS is the Schirmer tear test (STT); it measures the quantity of the lacrimal secretion. The STT was experimented by the German ophthalmologist, Otto Schirmer, approximately one century ago ${ }^{41}$ This check was used in both human and veterinary ophthalmology as a basic rating of tear production. ${ }^{42}$ Nowadays, it remains the standard test used to evaluate tear productions in the canine eye. ${ }^{42}$ Diagnosis of KCS in dog is achieved by measurement of both basal and reflex tear production using Schirmer tear test I (STT I). The Schirmer tear test II (STT II) is performed after the application of topical local anesthetic and is a measurement of basal tear production alone. ${ }^{10}$

Only the STT I on both eyes is done in the regular diagnostic procedure at the beginning of the visit. It is necessary to put inside the conjunctival fornix for a minute, a band made of absorbing, graduated, and sterile paper. Standard tear production in dogs is $>15 \mathrm{~mm} / \mathrm{min}$. All values between $10 \mathrm{~mm} /$ $\min$ and $15 \mathrm{~mm} / \mathrm{min}$ are doubtful, while dogs with values between $5 \mathrm{~mm} / \mathrm{min}$ and $10 \mathrm{~mm} / \mathrm{min}$ are suspicious. If the STT is $<5 \mathrm{~mm} / \mathrm{min}$, the diagnosis of KCS is sure. In case atropine has been administered some days before, the result is altered. In fact, it can cause temporary dryness (2-6 days) though it is more common in cats than in dogs. It is also necessary to say that diurnal variation in canine tear production as determined by STT I has been reported with highest levels in the late afternoon and lowest level at midday, which was between 10 am and 4 pm STT I. ${ }^{8,10}$ Nevertheless, there are studies that do not confirm these variations. ${ }^{43}$ Furthermore, significant differences were found in both STT I and STT II values between dogs of different body weights. The differences in the STT I and II values reflecting basal tear production between dogs of different body weights were striking. Large dogs have higher basal tear production when compared with dogs of lesser body weight. ${ }^{44}$ To confirm the STT I values, a recent study done by Biondi et al, in 2015 applied infrared thermography. This technique was used to measure temperature differences of the corneal surface between nasal and temporal limbus regions and central cornea of normal dogs and animals with KCS. The mean corneal temperature was greatly lower in eyes with low STT. So, thermography is a method that can be used to discern between eyes with normal and abnormal STT values. ${ }^{45}$

\section{Medical treatment}

Medical therapy aims to eliminate the cause when possible, to reactivate the tear film, to stimulate tears, to control and prevent secondary bacterial infections, and to 
reduce inflammation. It is based on the use of artificial tear drops, acetylcysteine, antibiotics, corticosteroids, pilocarpine, but the most important ones are the lacrimostimulant agents; but the new therapy for KCS is the local use of NGF. Usually, it is necessary to use the therapy life long, and so it is really important to explain in detail the whole situation to the owner. Before starting therapy, it is crucial to remove secretions from around the eyes many times a day to minimize irritation of the eyelids, conjunctiva, and cornea. It is essential to cleanse the area gently with clean and wet small gauze.

Gel artificial tear drops: They are the first drugs to be administered to give relief to the tissues, to the cornea, and to the conjunctiva. They must be applied quite often, especially if the STT I values are between $0 \mathrm{~mm} / \mathrm{min}$ and $5-7 \mathrm{~mm} / \mathrm{min}$ (once an hour if possible). If the STT I values are $>7$, it is possible to reduce the quantity, but never below six times a day.

Acetylcysteine: It is a mucolytics agent, and it can be used in the initial phases of KCS when there is an eye discharge linked to a mucin excess on the ocular surface.

Antibiotics: It is also necessary to use topical antibiotics, especially during the first phases of the therapy to contrast the secondary bacteria infections that are common in KCS. Corticosteroids: Short-term application of corticosteroids may improve symptoms but they should be used with utmost caution due to the common occurrence of corneal ulceration with KCS. Long-term use should be avoided, especially in dogs with lagophthalmos and exophthalmos because of the high risk of ulcer.

Pilocarpine: It is a parasympathomimetic agent that can be beneficial in KCS with neurogenic origin if given by oral or topic route. ${ }^{46}$ It will likely not help most animals with immune-mediated KCS. The $0.25 \%$ solution is applied on the affected eye(s) for every 6 hours. In case of eye drops, oral pilocarpine $1 \%-2 \%$ eye drops must be mixed with the food with the following dose: $1 \mathrm{drop} / 10 \mathrm{~kg}$ body weight for every 12 hours. ${ }^{28}$ Side effects of oral pilocarpine can be diarrhea, drooling, vomiting, or drop in heart rate. This is the reason why If the dog's weight is $<5 \mathrm{~kg}$ it is good to use only $1 \%$ pilocarpine.

Immunosuppressive drug: When treating $\mathrm{KCS}$, the main therapies to support tear drops are the cyclosporine A (CsA), pimecrolimus, and tacrolimus. It is a powerful immunosuppressive drug activity and stimulates tear production in dogs.

CsA was isolated from the fungus Tolypocladium inflatum in $1976 .{ }^{38}$ It is lipophilic, neutral cyclic undecapeptide and is the first immunosuppressant to have a selective effect on lymphoid or T-cells. This effect on T-cells is unique: at therapeutic concentrations, it inhibits T-cells proliferation but it is noncytotoxic. ${ }^{47} \mathrm{CsA}$ has potent immunosuppressive properties, reflecting its ability to block the transcription of cytokine genes in activated T-cells. ${ }^{48}$

Administering CsA will improve the following: stop the aggression of the lachrymal gland; stop the inflammatory process evidently diminishing cornea and conjunctiva lesions; and restore eye lubrication.

CsA has also been shown to enhance mucin production from conjunctival goblet cells. Therefore, its effects are also beneficial in enhancing tear film stability and the use is indicated in cases of qualitative tear deficiency as well.

This drug has been administered topically as a $0.2 \%$ ointment and as a $1 \%$ or $2 \%$ oil-based solution. $36,38,49$

Achievable results when applying CsA can vary according to the initial condition of the animal, and the first signs of improvement can only be seen after the 1 st or 2 nd month of treatment. Initially, it must be administered twice a day, then, in case of positive results, once a day. If the treatment is interrupted, clinical signs will reappear.

A research made in 2010 aimed to study the therapeutic effect of CsA on immune-mediated canine KCS. ${ }^{5}$ The study was conducted on 12 dogs with a total of 24 eyes, the dogs were in various ages ranging from 3 years to 11 years and different sexes - nine males and three females. They all underwent the following examinations: cornea evaluation by slit lamp, fluorescent staining, STT I, and corneal and conjunctival cytology. All animals showed different stages of the disease. Some of them had evident signs of mucopurulent filaments and redness; they were negative to fluorescein. STT I on right eye was $4.4 \pm 2.5 \mathrm{~mm} / 1 \mathrm{~min}$ and on left eye was $5.5 \pm 2.3 \mathrm{~mm} / 1 \mathrm{~min}$. The animals were all topically treated (twice a day) with CsA ointment $0.2 \%$ for 8 weeks. The events confirmed the results observed in the previous studies. Thus, there was a great increase in the STT I (the right eye was $12 \pm 4.6 \mathrm{~mm} / 1 \mathrm{~min}$ and left eye was $11.8 \pm 4.1 \mathrm{~mm} / 1 \mathrm{~min}$ ). Moreover, dogs treated with CsA showed a diminishing purulent corneal secretion and displayed marked regression of chronic corneal neovascularization and granulation tissue. This decrease in inflammation was confirmed by the impression cytology analysis. It underlined a significant reduction in the number of corneal inflammatory cells. ${ }^{50}$ However, it is important to note that there are a number of canine KCS patients that do not respond to CsA treatment. ${ }^{1}$ During these last years, there have been new forms of medication able to locally suppress immunity such as pimecrolimus and tacrolimus. 
Pimecrolimus (SDZ ASM 981; Novartis Pharma AG, Basel, Switzerland) is a new ascomycin derivative. It facilitates the activation of T-cells and mast cells, and by this way, it inhibits the production of inflammatory cytokines. ${ }^{11}$ In 2009, Ofri et al. made a research to evaluate both the capacity of pimecrolimus oil-based eye drops and the CsA ointment. It showed that pimecrolimus $1 \%$ has a better action than CsA. Therefore, pimecrolimus can be considered as a new successful local therapy for KCS in dogs. ${ }^{11}$

Tacrolimus (formerly FK506) is a macrolide antibiotic from Streptomyces tsukubaensis that shows similarities with the immunomodulatory action of CsA. ${ }^{51}$ These similarities are on the effects of T-cell-mediated ocular disease. ${ }^{1}$ In 2005, Berdoulay et al demonstrated that the administration of $0.02 \%$ tacrolimus in aqueous suspension twice a day effectively increases tear production. Therefore, the topical administration of tacrolimus can be used on animals that do not have any reactions to local CsA.

NGF: During the past few years, there have been many researches on the use of growth factor in ocular therapy. The NGF received a lot of attention. At the beginning, it was defined as a target-derived neurotrophin. Observation demonstrated, in fact, that it was produced during the growth and the differentiation of neural cells. ${ }^{52}$ Nevertheless, a recent research showed that NGF is also produced by both structural and immune cells during the inflammation and the healing of the cornea. This confirms that NGF has an action not only in the neural tissue but also in many others. ${ }^{53}$ Preliminary data, in fact, show that NGF may improve tear production in humans too. ${ }^{54}$

Studies demonstrate that NGF is involved in the pathophysiology of the ocular surface and that NGF receptors are expressed by conjunctival and corneal epithelial cells..$^{55-57}$ A validation to the possible positive action of NGF on dog's eye comes from the author experience in a research made in 2009. It was meant to evaluate the tear level of NGF in 12 normal dogs. The dogs were of different sexes, breeds, and ages ranging from 2 years to 12 years old. Tears were collected by washing the eye surface and tested for the presence of NGF, using a commercially available immunoenzymatic assay. All samples showed the presence of NGF. This suggested that this growth factor is a constitutive biological mediator of the ocular surface. It also confirms that this molecule may be involved in the regulation of corneal homeostasis. ${ }^{9}$

The effectiveness of NGF was also evaluated in dogs affected by KCS. In an experimental research, topical application of NGF was evaluated in dogs with surgically induced dry eye. ${ }^{54}$ This is confirmed in the author experi- ence in a study made in 2007-2008 on spontaneous KCS to evaluate the potential therapeutic action of this molecule. The study was conducted on six dogs with different sexes, breeds, and ages ranging from 2 years to 10 years affected by dry eye, presenting STT I on right eye $5.8 \pm 2.0 \mathrm{~mm} / 1 \mathrm{~min}$ and on the left one it was $6.0 \pm 1.4 \mathrm{~mm} / 1 \mathrm{~min}$. The dogs were topically treated with purified murine NGF diluted in paraffin oil for 4 weeks (twice a day for 4 weeks). The results of this treatment showed a significant improvement in STT I. Thus, the right eye was $13.1 \pm 2.4 \mathrm{~mm} / 1 \mathrm{~min}$ and the left eye was $14.0 \pm 2.4 \mathrm{~mm} / 1 \mathrm{~min}$. Moreover, dogs treated with NGF showed a decreased redness and purulent corneal secretion. Furthermore, cytology analysis indicated a significant reduction in the number of corneal inflammatory cells too.

As a conclusion, it is important to note that NGF is involved in the regulation of tear production and it can cause an anti-inflammatory action on dog's cornea.

Nevertheless, further clinical studies are essential to assess the real consistency of this molecule and its therapeutic action in the case of KCS. ${ }^{58,59}$

\section{Surgical treatment}

If medical management of KCS is unsuccessful, surgical intervention should be considered. Surgical treatment is represented by parotid duct transposition (PDT), punctal occlusion, and permanent partial tarsorrhaphy. The options for surgical management are quite limited, with PDT being the most suitable choice in the majority of cases. ${ }^{60,61}$ Retrospective study of PDT in dogs reluctant to other medical treatments shows that it is a successful procedure based on clinical findings and in terms of owner perception. It has also been demonstrated that PDT improves ocular comfort and vision in medically refractive cases of KCS.${ }^{60}$ The other two procedures, punctual occlusion and permanent partial tarsorrhaphy, showed limited benefits in dogs affected with severe KCS. ${ }^{62,63}$

\section{Conclusion}

As already demonstrated, KCS is a frequent eye disease in all visited dogs with reported annual average incidences of $1 \%$. There are several known causes of KCS in dogs, but the immune-mediated one is the most frequent. At the very beginning, it appears as a common conjunctivitis and it is the reason why it is diagnosed as a banal primary bacterial infection. Therefore, it is a good practice to perform a STT I in all dogs suffering from keratoconjunctivitis and to make an early diagnosis to avoid the appearance of serious signs of the disease. Today, we have a powerful immunosuppressive 
drug activity that stimulates tear production in dogs. But in the future, may be and hopefully, we will use a growth factor as in the case of the NGF.

\section{Disclosure}

The author reports no conflicts of interest in this work.

\section{References}

1. Berdoulay A, English RV, Nadelstein B. Effect of topical $0.02 \%$ tacrolimus aqueous suspension on tear production in dogs with keratoconjunctivitis sicca. Vet Ophthalmol. 2005;8(4):225-232.

2. Kaswan RL, Salisbury MA. A new perspective on canine keratoconjunctivitis sicca. Treatment with ophthalmic cyclosporine. Vet Clin North Am Small Anim Pract. 1990;20:583-613.

3. Kaswan RL, Salisbury MA, Lothrup CD. Interaction of age and gender on occurrence of canine keratoconjunctivitis sicca. Prog Vet Comp Ophthalmol. 1991;1:93-97.

4. Helper LC. The tear film in the dog. Causes and treatment of diseases associated with overproduction and underproduction of tears. Anim Eye Res. 1996;15:5-11.

5. Moore CP. Diseases and surgery of the lacrimal secretory system. In: Gelatt KN, editor. Veterinary Ophthalmology. 3rd ed. Philadelphia, PA: Lippincott Williams \& Wilkins; 1999:583-607.

6. Williams DL. Immunopathogenesis of keratoconjunctivitis sicca in the dog. Vet Clin North Am Small Anim Pract. 2008;38(2):251-268.

7. de Almeida DE, Roveratti C, Brito FL, et al. Conjunctival effects of canine distemper virus-induced keratoconjunctivitis sicca. Vet Ophthalmol. 2009;12(4):211-215.

8. Aguirre GD, Rubin LF, Harvey CE. Keratoconjunctivitis sicca in dogs. J Am Vet Med Assoc. 1971;158(9):1566-1579.

9. Dodi PL, Zanotti C, Rossi S, Aloe L. Tear level of nerve growth factor in normal dogs. Acta Ophthalmol. 2009;87(s244):0. [Special Issue: Abstracts from the 2009 European Association for Vision and Eye Research Conference].

10. Hartley C, Williams DL, Adams VA. Effect of age, gender, weight, and time of day on tear production in normal dogs. Vet Ophthalmol. 2006;9(1):53-57.

11. Ofri R, Lambrou GN, Allgoewer I, et al. Clinical evaluation of pimecrolimus eye drops for treatment of canine keratoconjunctivitis sicca: a comparison with cyclosporine A. Vet J. 2009;179:70-77.

12. Gipson IK, Yankauckas M, Spurr-Michaud SJ, Tisdale AS, Rinehart W. Characteristics of a glycoprotein in the ocular surface glycocalyx. Invest Ophthalmol Vis Sci. 1992;33:218-227.

13. Herrera HD, Weichsler N, Gómez JR, de Jalón JA. Severe, unilateral, unresponsive keratoconjunctivitis sicca in 16 juvenile Yorkshire terriers. Vet Ophthalmol. 2007;10(5):285-288.

14. Westermeyer HD, Ward DA, Abrams K. Breed predisposition to congenital alacrima in dogs. Vet Ophthalmol. 2009;12(1):1-5.

15. Sanchez RF, Innocent G, Mould J, Billson FM. Canine keratoconjunctivitis sicca: disease trends in a review of 229 cases. J Small Anim Pract. 2007;48(4):211-217.

16. Barnett KC. Congenital keratoconjunctivitis sicca and ichthyosiform dermatosis in the Cavalier King Charles spaniel. J Small Anim Pract. 2006;47(9):524-528.

17. Hartley C, Donaldson D, Smith KC, et al. Congenital keratoconjunctivitis sicca and ichthyosiform dermatosis in 25 Cavalier King Charles spaniel dogs. Part I: clinical signs, histopathology, and inheritance. Vet Ophthalmol. 2012;15(5):315-326.

18. Hartley C, Barnett KC, Pettitt L, Forman OP, Blott S, Mellersh CS. Congenital keratoconjunctivitis sicca and ichthyosiform dermatosis in Cavalier King Charles spaniel dogs. Part II: candidate gene study. Vet Ophthalmol. 2012;15(5):327-332.

19. Miller PE, Panciera DL. Effects of experimentally induced hypothyroidism on the eye and ocular adnexa of dogs. Am J Vet Res. 1994; 55(5):692-697.
20. Cullen CL, Ihle SL, Webb AA, McCarville C. Keratoconjunctival effects if diabetes mellitus in dogs. Vet Ophthalmol. 2005;8(4):215-224.

21. Ciaramella P, Oliva G, Luna RD, et al. A retrospective clinical study of canine leishmaniasis in 150 dogs naturally infected by Leishmania infantum. Vet Rec. 1997;141(21):539-543.

22. Naranjo C, Fondevila D, Leiva M, Roura X, Peña T. Characterization of lacrimal gland lesions and possible pathogenic mechanisms of keratoconjunctivitis sicca in dogs with leishmaniosis. Vet Parasitol. 2005; 133(1):37-47.

23. Soontornvipart K, Rauser P, Kecov H, Lexmaulová L. Effect of anaesthetic premedication with medetomidine-buprenorphine on the aqueous tear production in dogs. Acta Vet Brno. 2003;72:267-272.

24. Berger S, Scagliotti R, Lund E. A quantitative study of the effects of Tribrissen on canine tear production. J Am Anim Hosp Assoc. 1995; 31(3):236-241.

25. Trepanier LA. Idiosyncratic toxicity associated with potentiated sulfonamides in the dog. $J$ Vet Pharmacol Ther. 2004;27(3): $129-138$.

26. Klauss G, Giuliano EA, Moore CP, et al. Keratoconjunctivitis sicca associated with administration of etodolac in dogs: 211 cases (1992-2002). J Am Vet Med Assoc. 2007;230(4):541-547.

27. Ruehlmann D, Podell M, March P. Treatment of partial seizures and seizure-like activity with felbamate in six dogs. J Small Anim Pract. 2001;42(8):403-408

28. Matheis FL, Walser-Reinhardt L, Spiess BM. Canine neurogenic keratoconjunctivitis sicca: 11 cases (2006-2010). Vet Ophthalmol. 2012; 15(4):288-290.

29. Miller PE. Lacrimal system. In: Maggs DJ, Miller PE, Ofri R, editors. Slatter's Fundamentals of Veterinary Ophthalmology. 4th ed. St Louis: Saunders Elsevier; 2008:166-171.

30. Saito A, Izumisawa Y, Yamashita K, Kotani T. The effect of third eyelid gland removal on the ocular surface of dogs. Vet Ophthalmol. 2001; 4(1):13-18.

31. Dugan SJ, Severin GA, Hungerford LL, Whiteley HE, Roberts SM. Clinical and histological evaluation of the prolapsed third eyelid gland in dogs. J Am Vet Med Assoc. 1992;201(12):1861-1867.

32. Morgan RV, Duddy JM, McClurg K. Prolapse of the gland of the third eyelid in dogs: a retrospective study of 89 cases (1980 to 1990). $\mathrm{J} \mathrm{Am}$ Anim Hosp Assoc. 1993;29:56-60.

33. Dehghan MM, Pedram MS, Azari O, Mehrjerdi HK, Azad E. Clinical evaluation of the pocket technique for replacement of prolapsed gland of the third eyelid in dogs. Turk J Vet Anim Sci. 2012;36(4): 352-356.

34. Gelatt KN, Peiffer RL Jr, Erickson JL, Gum GG. Evaluation of tear formation in the dog, using a modification of the Schirmer tear test. J Am Vet Med Assoc. 1975;166:368-370.

35. Kaswan RL. Keratoconjunctivitis sicca: immunological evaluation of 62 cases. Am J Vet Res. 1985;46:376-383.

36. Kaswan RL, Martin CL, Chapman WL. Keratoconjunctivitis sicca: histopathologic study of nictitating membrane and lacrimal glands from 28 dogs. Am J Vet Res. 1984;45(1):112-118.

37. Bounous DI, Carmichael KP, Kaswan RL, et al. Effects of ophthalmic cyclosporine on lacrimal gland pathology and function in dogs with keratoconjunctivitis sicca. Vet Ophthalmol. 1996;5:5-12.

38. Morgan RV, Abrams KL. Topical administration of cyclosporine for treatment of keratoconjunctivitis sicca in dogs. $J$ Am Vet Med Assoc. 1991;199(8):1043-1046.

39. Gilger BC, Allen JB. Cyclosporine A in veterinary ophthalmology. Vet Ophthalmol. 1998;1(4):181-187.

40. Sansom J, Barnett KC. Keratoconjunctivitis sicca in the dog: a review of two hundred cases. J Small Anim Pract. 1985;26:121-131.

41. Schirmer O. Studien zur physiologie und pathologie der traneabsonderung und tranenabfuhr [Studies on physiology and pathology of tears secretion and removal]. Graefes Arch Klin Exp Ophthalmol. 1903;56:197-291. [German].

42. Williams DL. Analysis of tear uptake by the Schirmer tear test strip in the canine eye. Vet Ophthalmol. 2005;8(5):325-330. 
43. Hamor RE, Roberts SM, Severin GA, Chavkin MJ. Evaluation of results for Schirmer tear tests conducted with and without application of a topical anesthetic in clinically normal dogs of 5 breeds. Am J Vet Res. 2000;61(11):1422-1425.

44. Berger SL, King VL. The fluctuation of tear production in the dog. JAm Anim Hosp Assoc. 1998;34(1):79-83.

45. Biondi F, Dornbusch PT, Sampaio M, Montiani-Ferreira F. Infrared ocular thermography in dogs with and without keratoconjunctivitis sicca. Vet Ophthalmol. 2015;18(1):28-34.

46. Crispin S. Notes on Veterinary Ophthalmology. 1st ed. Oxford: Blackwell Publishing; 2005:97-99.

47. Schreiber SL, Crabtree RR. The mechanism of action of cyclosporin A and FK506. Immunol Today. 1992;13(4):136-142.

48. Matsuda S, Koyasu S. Mechanisms of action of cyclosporine. Immunopharmacology. 2000;47(2-3):119-125.

49. Salisbury MA, Kaswan RL, Ward DA, et al. Topical application of cyclosporine in the management of keratoconjunctivitis sicca in dogs. J Am Anim Hosp Assoc. 1990;26:269-274.

50. Dodi PL, Bianchi E, Quintavalla F. Cyclosporine A topical administration in dogs affected by immune-mediated keratoconjunctivitis sicca. Acta Ophthal Scand Suppl. 2010;88(s246):0. [Special Issue: Abstracts from the 2010 European Association for Vision and Eye Research Conference].

51. Kino T, Hatanaka H, Hashimoto M, et al. FK506, a novel immunosuppressant isolated from Streptomyces. I. Fermentation, isolation, and physio-chemical and biological characteristics. J Antibiot (Tokyo). 1987;60:1249.

52. Levi-Montalcini R. The nerve growth factor 35 years later. Science. 1987;237:1154-1162.

53. Kang SS, Ha SJ, Kim ES, Shin JA, Kim JY, Tchah H. Effect of nerve growth factor on the in vitro induction of apoptosis of human conjunctival epithelial cells by hyperosmolar stress. Invest Ophthalmol Vis Sci. 2014;55(1):535-541.
54. Coassin M, Lambiase A, Costa N, et al. Efficacy of topical nerve growth factor treatment in dogs affected by dry eye. Graefes Arch Clin Exp Ophthalmol. 2005;243(2):151-155.

55. Lambiase A, Rama P, Bonini S, Caprioglio G, Aloe L. Topical treatment with nerve growth factor for corneal neurotrophic ulcers. N Engl J Med. 1998;338(17):1174-1180.

56. Lambiase A, Bonini S, Micera A, Rama P, Bonini S, Aloe L. Expression of nerve growth factor receptors on the ocular surface in healthy subjects and during manifestation of inflammatory diseases. Invest Ophthalmol Vis Sci. 1998;39(7):1272-1275.

57. Lambiase A, Manni L, Bonini S, Rama P, Micera A, Aloe L. Nerve growth factor promotes corneal healing: structural, biochemical, and molecular analyses of rat and human corneas. Invest Ophthalmol Vis Sci. 2000;41(5):1063-1069.

58. Dodi PL, Zanotti C, Costa N, Aloe L. NGF topical administration in dogs affected by spontaneous keratoconjunctivitis sicca. Acta Ophthalmol Scand Suppl. 2007;85(s240):0. [Special Issue: Abstracts from the 2007 European Association for Vision and Eye Research Conference].

59. Dodi PL, Zanotti C, Costa N, Aloe L. Topical use of nerve growth factor on ocular flora and cytology in dogs eye surface. Acta Ophthal Scand Suppl. 2008;86(s243):0. [Special Issue: Abstracts from the 2008 European Association for Vision and Eye Research Conference].

60. Rhodes M, Heinrich C, Featherstone H, et al. Parotid duct transposition in dogs: a retrospective review of 92 eyes from 1999 to 2009. Vet Ophthalmol. 2012;15(4):213-222.

61. Lewin A. Keratoconjunctivitis sicca in dogs: causes, diagnosis and treatment. Vet Times. 2014;6(2014):16-17.

62. Gelatt KN, MacKay EO, Widenhouse C, Widenhouse TS, Stopek JB. Effect of lacrimal punctal occlusion on tear production and tear fluorescein dilution in normal dogs. Vet Ophthalmol. 2006;9(1):23-27.

63. Giuliano EA, Moore CP. Diseases and surgery of the lacrimal secretory system. In: Gelatt KN, editor. Veterinary Ophthalmology. 4th ed. Iowa: Wiley-Blackwell; 2007:633-661.
Veterinary Medicine: Research and Reports

\section{Publish your work in this journal}

Veterinary Medicine: Research and Reports is an international, peer-reviewed, open access journal publishing original research, case reports, editorials, reviews and commentaries on all areas of veterinary medicine. The manuscript management system is completely online and includes a very quick and fair peer-review system.

\section{Dovepress}

Visit http://www.dovepress.com/testimonials.php to read real quotes from published authors. 